\title{
Perspectivas antirracistas no ensino de Ciências e Matemática: Uma análise da Base Comum Curricular de Esteio/RS
}

\author{
Anti-racist perspectives in Science and Mathematics teaching: An \\ analysis of the Common Curricular Base of Esteio/RS
}

\author{
Michele Assis de Oliveira (assis.miche89@gmail.com) \\ Universidade Federal do Rio Grande do Sul, UFRGS \\ Marilisa Bialvo Hoffmann (marilisa.ufrgs@gmail.com) \\ Universidade Federal do Rio Grande do Sul, UFRGS
}

\begin{abstract}
Resumo: Uma educação antirracista envolve a relação e o convívio entre pessoas e estrutura social. Este convívio é ampliado no ambiente escolar, pois é neste espaço que crianças e jovens estabelecem novas relações sociais com pessoas de diferentes etnias, gêneros e identidades. Tais relações acabam por influenciar diretamente a construção da autoimagem de cada indivíduo. Assim, a educação antirracista é aquela que atua de modo a permitir que todos tenham sua identidade e história acolhida no espaço escolar. Para além do processo de ensino conteudista, um dos principais desafios éticos do ensino dos componentes curriculares nas escolas é a garantia do reconhecimento e valorização da pluralidade do patrimônio sociocultural brasileiro. A presente pesquisa, por meio de análise documental, examina a Base Municipal Comum Curricular do Ensino Fundamental do município de Esteio (RS), homologada no ano de 2017, sob a perspectiva antirracista, verificando se a temática da diversidade étnico-racial está presente nas diretrizes deste documento e, ainda, se há orientações para sua abordagem em sala de aula. Com a análise, constatou-se que a temática racial ainda não conquistou um espaço de destaque na prática pedagógica e que existem lacunas visíveis nas orientações do documento.
\end{abstract}

Palavras-chave: Educação Inclusiva; Educação Antirracista; Currículo.

Abstract: An anti-racist education involves the relationship and coexistence between people and social structure. This interaction is extended in the school environment, the space that children and young people establish new social relationships with people of different ethnicities, genders and identities. Such relationships directly influence the construction of each individual's self-image. Thus, anti-racist education allows everyone to have their identity and history embraced in the school space. In addition to the content teaching process, one of the main ethical challenges in teaching curriculum components in schools is ensuring the recognition and appreciation of the plurality of Brazilian socio-cultural heritage. This research, by means of documentary analysis, examines the Common Municipal Curricular Base of Elementary Education in the municipality of Esteio (RS), approved in 2017, under the anti-racist perspective, checking if the theme of ethnic-racial diversity is present in this document and also if there are guidelines for its approach in the classroom. With the analysis, it was found that the racial theme has not yet achieved a prominent place in pedagogical practice and that there are visible gaps in the document's guidelines.

Aceito em: 24/02/2021 
Keywords: Inclusive education; Anti-racist Education; Curriculum.

\section{INTRODUÇÃO}

O Brasil oferece um exemplo de país que nasceu do encontro das diversidades: povos indígenas, europeus, orientais e africanos de diferentes matrizes étnicas ou culturais. Todos, sem exceção, deram suas notáveis contribuições para a formação do povo brasileiro, para a construção de sua cultura e de sua identidade plural (MUNANGA, 2008; 2010). A necessidade de estudos sobre a diversidade advém do fato de ainda persistirem arraigados no imaginário social, preconceitos de diversas ordens. Logo, é necessário avançar no sentido de desnaturalizar essas percepções apontando possíveis caminhos para mitigar e acabar com as diferentes formas de intolerância.

Então, pode-se afirmar que toda escola que insere a temática da diversidade de maneira interdisciplinar e que dialoga com o cotidiano do discente em seu planejamento escolar possibilita a promoção do respeito às diferenças, comprometendo-se com a formação de cidadãos críticos e questionadores. Do mesmo modo, conforme enfatiza Verrangia (2010), há uma importância consensual, na área de Educação, de vincular o ensino à realidade dos/as alunos/as e às suas vivências concretas e socioculturais. Desse modo, a prática educacional que traz o pensamento crítico, reflexivo e desconstrutivo para a sala de aula avança na direção de uma atuação que liberte as minorias da opressão. Portanto, está em consonância com os estudos de Freire, que já alertavam para a prática de uma Pedagogia da autonomia: "nas condições de verdadeira aprendizagem os educandos vão se transformando em reais sujeitos da construção e da reconstrução do saber ensinado, ao lado do educador, igualmente sujeito do processo" (FREIRE, 2015, p. 28).

O preconceito presente em nossa sociedade deixa rastros de desigualdade na área da educação. Há maior taxa de analfabetismo e evasão escolar entre negros e pardos (IBGE, 2018), pois estes indivíduos não entendem o ambiente escolar como seu espaço de pertencimento, uma vez que a realidade apresentada em sala de aula não dialoga com aquela realidade vivenciada por eles em seus cotidianos (SILVA, 2019). 
Conforme a Pesquisa Nacional por amostra de Domicílios de 2018 (PNAD), realizada pelo Instituto Brasileiro de Geografia e Estatísticas (IBGE), no que diz a respeito à taxa de acesso à educação básica - obrigatória pela Constituição no país -, entre negros e pardos o índice fica em 40,3\%, enquanto entre brancos é de 55,8\%. Já a média de anos de estudo é 10,3 anos para as pessoas de cor branca e 8,4 anos para as de cor preta ou parda. Ainda, a taxa de frequência escolar do ensino médio para jovens (15 a 17 anos) é menor para pretos ou pardos $(64,9 \%)$ com relação a brancos da mesma idade $(76,5 \%)$. A PNAD também buscou conhecer a aproximação com o trabalho e com o estudo ou a qualificação para o trabalho entre jovens de 15 a 29 anos, constatando que a taxa de pessoas brancas que não se qualificam nem trabalham é $18,5 \%$, enquanto $25,8 \%$ de pessoas pretas ou pardas encontram-se nessa situação. Por fim, sobre a taxa de analfabetismo, esta também é maior entre pessoas pretas ou pardas, somando cerca de 9,1\%, enquanto entre pessoas brancas é de 3,9\% (IBGE, 2018).

As taxas apresentadas são exemplos das necessidades que corroboram com a importância de incluir no cotidiano escolar diretrizes que superem o racismo e as desigualdades sociais. É importante que as estratégias viabilizem um ambiente em sala de aula mais acolhedor às diversidades e com uma menor taxa de evasão escolar de alunos negros e pobres, pois a escola é uma instituição capaz de contribuir para a superação da intolerância, das desigualdades e do racismo por meio de conhecimento. As Diretrizes que deram embasamento à temática do Ensino para as Relações ÉtnicoRaciais foram homologadas em 2004 e, a partir daí, começaram a se fazer presentes nas normatizações estabelecidas pelo Ministério da Educação (MEC) com o objetivo de regular o exercício da temática no ensino fundamental e médio.

Foram estabelecidos, assim, o parecer e a resolução que instituíram as Diretrizes Curriculares Nacionais para a Educação das Relações Étnico-Raciais e para o ensino de história e cultura afro-brasileira e africana, aprovados pelo Conselho Nacional de Educação (CNE) em março de 2004 e homologados pelo Ministério da Educação (MEC) em junho do mesmo ano. A resolução foi resultante do Parecer CNE/CP 3/2004, que também estabelece as orientações sobre os conteúdos a serem incluídos nos currículos em todos os níveis da educação básica, além de traçar estratégias pedagógicas "de valorização da diversidade e combate ao racismo, que competem a todos/as os/as 
Edição Especial: I SSAPEC - Simpósio Sul-Americano de Pesquisa em Ensino de Ciências

professores/as que atuam na educação básica, independentemente do seu pertencimento étnico-racial" (BRASIL, 2004).

Dessa forma, verifica-se a importância destas diretrizes no sentido de quebrar a hegemonia de currículos monoculturais e eurocêntricos. A atenção no atendimento à implantação da Lei Federal n 10.639/03, que tornou obrigatório o ensino da história e cultura afro-brasileira e africana em todas as escolas, públicas e particulares, do ensino fundamental até o ensino médio, desempenha um papel fundamental para a viabilização da valorização das diferenças culturais e a promoção da equidade étnico-racial. As diretrizes buscaram criar recursos para fortalecer a representatividade das populações de origem africana e de outros pertencimentos étnicos, bem como o reconhecimento desses sujeitos como de extrema importância para a constituição e a manutenção da sociedade brasileira.

Porém, como apontou a pesquisa do IBGE, o sistema educacional vigente ainda apresenta lacunas no que tange à temática da diversidade étnico-racial e à continuidade dos discentes de origem africana na escola. A implantação da Lei 10.639/03 adotou uma série de políticas educacionais e de estratégias pedagógicas de valorização da diversidade. Sua aplicação resultou em programas de ações afirmativas, visando corrigir desvantagens criadas por uma estrutura social excludente e discriminatória.

Nesse movimento incessante pela busca da conquista dos direitos das populações de origem africana, é importante ressaltar o protagonismo do Movimento Negro na implantação destas leis e na luta por uma educação antirracista, democrática e com foco em uma educação para diversidade sociocultural e não somente com viés eurocêntrico. A necessidade do entendimento de práticas que promovam a Educação para as Relações Étnico-Raciais (ERER) surge a partir das demandas nacionais e internacionais para o combate ao racismo e outras formas de preconceitos e intolerâncias que geram violências na sociedade e acabam por atingir os espaços escolares. Estas demandas foram levantadas historicamente pelas populações marginalizadas, com destaque para os movimentos de libertação, emancipação e reconhecimento empreendidos pelo Movimento Negro. Em meio a essa trajetória de luta, são marcos os levantes de Zumbi dos Palmares e Ganga Zumba no Brasil do século XVII, bem como no ano de 2001, quando aconteceu a Conferência Internacional de Durban, na África do Sul, em que o 
governo brasileiro tornou-se signatário de uma Declaração com diversos compromissos ${ }^{1}$ a implementar (CARTH, 2018).

Nosso objetivo foi verificar a abordagem da temática étnico racial no documento especificamente nas áreas de Ciências da Natureza e Matemática, analisando se nestas encontram-se o reconhecimento e a valorização da cultura afro-brasileira e indígena.

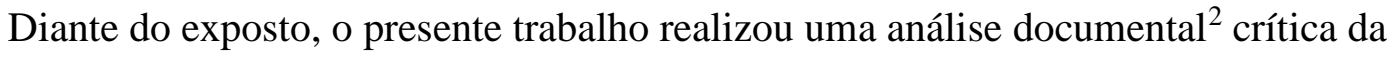
Base Municipal Comum Curricular do município de Esteio no Estado do Rio Grande do Sul, amparada pela legislação vigente nas temáticas, como: a Lei 10.639/03, as Diretrizes Curriculares Nacionais, a Base Nacional Comum Curricular, bem como produções científicas (de graduação, mestrado e doutorado) pertinentes ao tema.

A Base Nacional Comum Curricular (BNCC), que dá origem à Base Municipal Comum Curricular (BMCC), institui-se como referência nacional para a elaboração de currículos dos sistemas de ensino e das propostas pedagógicas das escolas. Ela também alinha políticas e ações em torno da formação de professores, avaliação e critérios de infraestrutura para o desenvolvimento da educação (NEIRA, 2018), constituindo-se desta forma como documento norteador para a elaboração da Base Comum Curricular do município de Esteio, que é o objeto de estudo do presente trabalho. Deste modo, trazemos na sequência um breve detalhamento do que é a BNCC, entrando a seguir em dados específicos da pesquisa.

\section{O QUE É A BNCC?}

Inicialmente, será analisada a Base Nacional Comum Curricular (BNCC), bem como sua importância quanto documento normativo para as redes de ensino de todo o país.

${ }^{1}$ A III Conferência Mundial contra o Racismo, a Discriminação Racial, a Xenofobia e Formas Correlatas de Intolerância, promovida pela Organização das Nações Unidas (ONU), ocorreu de 31 de Agosto a 8 de Setembro de 2001, em Durban na África do Sul. Ao ser signatário do Plano de Ação de Durban, o Estado brasileiro reconheceu internacionalmente a existência institucional do racismo em nosso país e se comprometeu a construir medidas para a sua superação. Entre elas, ações afirmativas na educação e no trabalho (GOMES, 2017, p.34).

${ }^{2}$ A análise documental se constitui como aquela realizada a partir de documentos considerados cientificamente autênticos, avaliada como uma técnica importante na pesquisa qualitativa (Ludke e André, 1986). 
A Base Nacional Comum Curricular (BNCC) é uma das estratégias estabelecidas pelo Plano Nacional de Educação (PNE) para melhorar a educação básica, que abrange a educação infantil, o ensino fundamental e o médio. A BNCC começou a ser elaborada em 2015 a partir de uma análise aprofundada dos documentos curriculares brasileiros. Foi realizada por 116 especialistas indicados por secretarias municipais e estaduais de educação e por universidades, nos anos de 2015 e 2016. Ademais, consultas públicas presenciais e on-line foram realizadas para possibilitar a participação mais direta da população na sua construção. Em 2017, considerando as versões anteriores do documento, o MEC concluiu a sistematização das contribuições e encaminhou uma terceira e última versão do texto ao Conselho Nacional de Educação (CNE). O documento da Base foi homologado pelo Ministério da Educação (MEC) no dia 20 de dezembro de 2017 para as etapas da Educação Infantil e Ensino Fundamental. A seguir, em 14 de dezembro de 2018, o documento foi homologado para a etapa do Ensino Médio. Ambos estão em vigor nas redes e sistemas de ensino do país (BRASIL, 2020).

A BNCC define os conhecimentos e habilidades que todos os alunos brasileiros têm o direito de aprender, ano a ano, na Educação Básica. Como define a Lei de Diretrizes e Bases da Educação Nacional (LDB, Lei n 9.394/1996), o documento norteia a formulação dos currículos dos sistemas e das redes de ensino dos estados, do Distrito Federal e dos municípios. A orientação estabelece conhecimentos, competências e habilidades que devem ser desenvolvidos por todos os estudantes ao longo da escolaridade básica (BRASIL, 2020). Com a BNCC, os sistemas educacionais, as escolas e os professores têm um importante referencial para suas aulas.

A decisão de ter uma base comum visa contribuir para a promoção da equidade e da qualidade, pois um sistema educacional precisa de um documento claro e objetivo, que respeite as diversidades e autonomia locais e que promova uma aprendizagem que faça sentido para todos discentes. Na última década, dados de avaliações externas, como o SAEB (Sistema Nacional de Avaliação da Educação Básica), têm apontado ao sistema de educação Municipal que as propostas pedagógicas desenvolvidas pelas unidades escolares não estão sistematizadas enquanto uma rede de ensino. Dessa forma, surgiu a necessidade da criação de uma Base Municipal Comum Curricular, por meio da qual os currículos da rede municipal são adaptados à realidade do/a discente de cada município. 
Edição Especial: I SSAPEC - Simpósio Sul-Americano de Pesquisa em Ensino de Ciências

ISSN: 2595-4520 Vol. 4, n. 3. 2021

Na sequência, faremos uma breve contextualização do município de Esteio, no Rio Grande do Sul, de onde analisamos a BMCC.

\section{O MUNICÍPIO DE ESTEIO (RS)}

Nesta seção, serão abordadas as principais características acerca do município de Esteio e o panorama educacional vigente na cidade.

O Município de Esteio está localizado a aproximadamente $20 \mathrm{~km}$ da capital do Rio Grande do Sul, Porto Alegre, e é parte da Região Metropolitana. Faz divisa com os municípios de Canoas, Nova Santa Rita, Sapucaia do Sul e Cachoeirinha. Possui população de 83.846 habitantes (BRASIL, 2014), embora seja o menor município em área da Região Sul do território brasileiro $\left(27.543 \mathrm{~km}^{2}\right)$. No âmbito educacional, existe no município desde a Educação Infantil até a Educação Profisssional (na forma de aulas presenciais) e o Ensino Superior (na proposta de aulas a distância).

Para atendimento às demandas de Educação Básica, estão em funcionamento no município 74 instituições de ensino da rede pública municipal, estadual e da rede privada. Dentre a totalidade de escolas, 23 são da rede municipal, organizadas, mantidas e oferecidas pela Secretaria Municipal de Educação. Elas ofertam desde a Educação Infantil até o $9^{\circ}$ ano do Ensino Fundamental, inclusive na modalidade de Educação de Jovens e Adultos. Destas, 12 são escolas mantidas pelo poder público estadual, organizadas e oferecidas pela Secretaria de Educação do Rio Grande do Sul através da $27^{\mathrm{a}}$ Coordenadoria Regional de Educação, localizada no município de Canoas (RS), ofertando o Ensino Fundamental e/ou Médio e também a modalidade de Educação de Jovens e Adultos; 37 são escolas da rede privada, dentre as quais 33 oferecem Educação Infantil; 7 oferecem Ensino Fundamental; e 4, Ensino Médio (BRASIL, 2014), no ensino sequencial regular da idade própria e na modalidade de Educação para Jovens e Adultos. O quantitativo de alunos atendidos anualmente no Município é de aproximadamente 20.000, sendo que a Educação Pública é a responsável por $76 \%$ das matrículas. Destas, 50\% estão na Rede Municipal e 26\% na Rede Estadual (BRASIL, 2014).

\section{A BMCC DO MUNICÍPIO DE ESTEIO}


A seguir, descreveremos de forma detalhada o planejamento necessário para a implantação da Base Municipal Comum Curricular no município de Esteio (RS), bem como as diretrizes utilizadas para a elaboração do documento.

A Base Municipal Comum Curricular do município de Esteio foi instituída e homologada em 20 de dezembro de 2017, e foi elaborada em colaboração com professores por áreas de conhecimento da Rede Municipal de Ensino (RME) de Esteio. Nesse processo, foram coletadas falas dos docentes em conjunto com a Secretaria Municipal de Educação da cidade, que permitiram construir competências e conceitos estruturantes mínimos desejáveis que os alunos do município desenvolvam. Conforme descrito no próprio documento, optou-se pela mistura de pensamentos e ações nessa construção porque se acredita que todo o material escrito, com a essência de muitos e, por aqueles que o utilizam diretamente, tem, em sua estrutura, uma maior autenticidade (ESTEIO, 2017).

Então, foi construído um Plano de Ação de Reestruturação Curricular e Capacitação Profissional da Rede Municipal, o qual descreveu passos que visaram atender aos objetivos do trabalho (ESTEIO, 2017) e serão descritos a seguir: a) Foi realizado o levantamento de todo o material construído pelas escolas (planos de estudos), etapa que refletiu sobre a valorização de registros já construídos e a necessidade de ouvir todas as escolas; b) Ocorreram nove encontros, sendo o primeiro com as Equipes Diretivas e os demais abordando as quatro áreas do conhecimento (Ciências Humanas, Ciências da Natureza, Linguagens e Matemática); c) Construção da arquitetura curricular da rede, realizada com auxílio dos materiais construídos pelos professores das áreas do conhecimento; d) Após essa arquitetura ser desenhada, todos os professores da Rede Municipal de Ensino tiveram a oportunidade de avaliar o que foi realizado e opinar sobre as construções e propor mudanças. Utilizando-se a internet como ferramenta digital colaborativa, foi construído um Blog, que apresentou a Planilha Descritiva dos Currículos Desenvolvidos, competências e conceitos divididos por componentes curriculares e ano escolar; e) Por fim, ocorreu um segundo bloco de encontros por área do conhecimento, nos quais os professores e a gestão escolar validaram o conteúdo do documento, ou seja, conferiram, discutiram e finalizaram sua construção. 
A BMCC que utilizou como referência a Base Nacional Comum Curricular, entrou em vigor no município no ano de 2018 e busca dar acesso às mesmas oportunidades de aprendizagem para todos os alunos, independentemente do local onde estudam. O poder público no município, com a implantação das diretrizes do documento, unificou o sistema educacional vigente na cidade.

A implantação de uma Base Comum Curricular no município de Esteio surgiu da necessidade de elevar o nível de aprendizagem dos alunos em âmbito escolar, bem como qualificar o ensino oportunizado na rede municipal, buscando coerência no processo de ensino-aprendizagem. De acordo com a equipe da Secretaria de Educação do município, uma das possíveis causas para o baixo desempenho dos estudantes foi a ausência de um currículo comum nas escolas municipais (ESTEIO, 2017). Desta forma, espera-se que com a implantação dessa diretriz curricular ocorra maior qualificação da ação docente e a potencialização da aprendizagem dos alunos.

\section{ANÁliSE DO DOCUMENTO, SOB A PERSPECTIVA DA} DIVERSIDADE ÉTNICO-RACIAL

Nesta seção, é realizada a análise do documento da BMCC nas áreas de Ciências e Matemática, sob uma perspectiva antirracista e que dialoga com as Diretrizes Curriculares Nacionais vigentes para a educação das relações étnico-raciais.

O documento apresenta os conhecimentos, competências e habilidades consideradas essenciais no processo de aprendizado dos estudantes ao longo da educação básica e servirá como referência para a formulação dos currículos dos sistemas e das redes escolares estaduais e municipais. O propósito é fazer com que as divergências entre os índices apresentados que estejam aquém do esperado possam diminuir gradativamente, por meio de um trabalho pedagógico mais coerente e alinhado, de forma que se perceba um crescimento na qualidade do trabalho oferecido aos alunos da Rede Municipal de Ensino (ESTEIO, 2017).

A BMCC do município está organizada por competências e habilidades de acordo com as áreas de aprendizagens específicas da Educação Básica (Linguagens, Matemática, Ciências da Natureza e Ciências Humanas). É ordenada em 9 capítulos, 
dispostos num total de 115 páginas, e disponibilizada para consulta em formato PDF no site oficial da Prefeitura Municipal de Esteio ${ }^{3}$.

No capítulo inicial do documento, somos remetidos a uma breve apresentação do corpo que compõe a Secretaria Municipal de Educação do município. Sequencialmente, é traçado um panorama geral da rede municipal de ensino, informando como é realizada a organização geral do currículo. Em seguida, são descritos em capítulos distintos as competências e habilidades das áreas de ensino específicas, iniciando pela área de Linguagens, seguido de Matemática, Ciências da Natureza e Ciências Humanas. O capítulo final é dedicado aos temas ditos "Transversais, Estruturantes e Contextualizados", que abrangem a temática da Diversidade (que envolve a diversidade étnico-racial, cultural, de gênero, de idade, entre outras), Educação Alimentar, Educação Ambiental/ Sustentabilidade, Educação Financeira e Fiscal e, por último, Educação para o Trânsito.

Conforme o documento, entre as "Competências do Aluno Esteiense" consta a expectativa de que o egresso da Educação Básica tenha como perfil desenvolvido no interior das escolas da rede municipal um aluno leitor e entendedor dos acontecimentos cotidianos, que reconhece a cientificidade na contextualização da realidade. $\mathrm{O}$ aluno será consciente do seu papel, tanto nas relações sociais como nas relações com o ambiente natural que o cerca, modificando realidades e desnaturalizando fenômenos (ESTEIO, 2017).

A BMCC é parte de todos os currículos locais que irão determinar as aprendizagens regionais e metodologias de ensino que julgar necessárias e adequadas. A partir daqui, analisaremos como cada área do conhecimento realiza a abordagem da temática étnico racial no documento da BMCC do município, quando esta se fizer presente.

\section{1 ÁREA DE MATEMÁTICA}

Nesta área do conhecimento, o aluno é incitado a resolver situações problema envolvendo diferentes circunstâncias (preferencialmente cotidianas), utilizando estratégias próprias e compreendendo as articulações existentes no contexto para afinar

\footnotetext{
${ }^{3}\langle$ http://www.esteio.rs.gov.br/images/arquivos/2017/bmcc esteio_ensino-fundamental.pdf $>$
} 
Edição Especial: I SSAPEC - Simpósio Sul-Americano de Pesquisa em Ensino de Ciências ISSN: 2595-4520 Vol. 4, n. 3. 2021

com criticidade a leitura de mundo (ESTEIO, 2017). Apesar da ausência de orientações específicas relacionadas ao ERER nesta área, é possível criar possibilidades para que o aluno possa raciocinar de forma autônoma, para com o reconhecimento de diferentes realidades. Por exemplo, a utilização de algoritmos matemáticos e de saberes matemáticos de diferentes povos, entre eles, os povos africanos, os quais podem ajudar na visibilização, no reconhecimento e na valorização de outros saberes, possibilitando um debate atual sobre o racismo, o preconceito e a discriminação racial. Além desse exemplo, existem diversas outras possibilidades, como explorar toda a geometria com suas figuras representadas por meio de símbolos da cultura Adinkra e de outras culturas africanas, e utilizar os antigos símbolos da arte yorubá para ajudar no entendimento de alguns conceitos geométricos (BRASIL, 2006, p.185).

As DCNs 03/2004 orientam a inclusão de atividades no ensino de Matemática que explorem as contribuições de raiz africana, identificadas e descritas pela Etnomatemática (BRASIL, 2004). A matemática faz parte da cultura e, portanto, deve ser um aprendizado em contexto situado do particular ao universal. Para a população de origem africana, em especial, é necessário tornar o ensino da matemática vivo, respeitando a cultura local. Isso é possível com base na história e na cultura dos povos, quando e como vivem, como comem, como se vestem, como rezam e como resolvem as questões cotidianas que envolvem os conhecimentos matemáticos (BRASIL, 2006, p.196).

\section{2 ÁREA DE CIÊNCIAS DA NATUREZA}

Essa área tem como principais ações educativas a aprendizagem para a vida, a interpretação de fenômenos de forma interdisciplinar, o desenvolvimento do poder investigativo, a utilização da ciência como elemento de interpretação e intervenção na sociedade, o desenvolvimento da capacidade de desnaturalizar os fenômenos com criticidade e a elaboração de propostas de ação em que seja possível reconhecer a cientificidade dos acontecimentos cotidianos, contextualizando socialmente fenômenos e questionando-os de forma crítica (ESTEIO, 2017). Dessa forma, corroborando com a citação de Silva (2011, p. 40), que afirma que o currículo é visto como experiência e como local de interrogação e questionamento da experiência. A biologia, a física e a química destacam-se como disciplinas que, quando integradas, são capazes de 
desconstruir afirmações que classificam as diferenças como inferioridade e que marcam a condição natural de indivíduos e grupos interétnicos (BRASIL, 2006, p.196).

O que ainda se deixa a desejar na maioria dos currículos é o fato destes terem tendência a enfatizar conteúdos das classes dominantes, refletindo os seus interesses. A escola é a instituição que tem um papel preponderante para a eliminação das discriminações e a emancipação dos grupos discriminados. Ela proporciona acesso aos conhecimentos científicos, a registros culturais diferenciados, à conquista de racionalidade - que rege as relações sociais e raciais - e a conhecimentos avançados, indispensáveis para a consolidação e união das nações como espaços democráticos e igualitários (BRASIL, 2004). É possível destacar que, no campo da biologia, o olhar do educador poderia recair sobre os estudos de epiderme, genética, constituição capilar e questões específicas da saúde da população afrodescendente, tais como pressão arterial elevada, anemia falciforme e os males que essas enfermidades causam. Parte das doenças que acometem a população negra de nosso país decorre de problemas sociais, entre eles o racial. Ou seja, são decorrentes de discriminação racial e de racismo institucional. Pesquisar as origens dessas doenças e maneiras de evitá-las é construir conhecimentos significativos (BRASIL, 2006, p. 196).

Ser sensível perante a diversidade é perceber que as relações sociais estão compreendidas em tempos e espaços distintos e simultâneos e que, destas relações, surgem culturas que disseminam diversidades. De acordo com Silva (2011, p. 103), currículo e cultura estão intimamente interligados, portanto, uma cultura não deve ser colocada como superior à outra. Dessa forma, o currículo deve ser pensado para atender as necessidades a partir das diferenças, valorizando o que cada cultura afirma como importante para a sua comunidade. É o que prioriza as DCNs para ERER de 2004, conforme o trecho a seguir do tópico "Consciência Política e Histórica da Diversidade":

à compreensão de que a sociedade é formada por pessoas que pertencem a grupos étnico-raciais distintos, que possuem cultura e história próprias, igualmente valiosas e que em conjunto constroem, na nação brasileira, sua história; (BRASIL, 2004)

Porém, ainda persiste em nosso país um imaginário étnico-racial que privilegia e valoriza principalmente as raízes europeias da sua cultura, ignorando ou pouco valorizando as outras. Sendo assim, o papel do currículo é crucial para a produção de uma intelectualidade que se coloque contra processos de colonização do saber, para que 
a questão racial passe a ocupar um lugar político e de destaque no campo da produção do conhecimento.

\subsection{TEMAS}

TRANSVERSAIS,

ESTRUTURANTES

$\mathbf{E}$

\section{CONTEXTUALIZADOS}

Este tópico engloba as temáticas acerca da Diversidade, Educação Alimentar, Educação Ambiental/Sustentabilidade, Educação Financeira e Fiscal e Educação para o Trânsito. O trabalho com esses temas deve perpassar e extrapolar diferentes conteúdos e atividades, desenvolvendo no estudante a capacidade de reflexão e ação sobre a leitura do espaço. Ainda conforme o documento, esses temas serão integrados no currículo transversalmente, ou seja, pretende-se que os mesmos estejam presentes em todas as áreas, relacionando-se às questões da atualidade e sendo orientadores do dia-a-dia escolar (ESTEIO, 2017). É no subtópico “diversidade” que as questões étnico-raciais serão tratadas com maior afinco, como podemos perceber no trecho abaixo:

Este tema envolve o respeito à diversidade étnico-racial, cultural, de gênero, de idade, dentre outras. O referido tema se encontra teorizado pelas Diretrizes Curriculares Nacionais da Educação Básica (DCNEB - 2013) e pela Base Nacional Comum Curricular (BNCC/2017 - $3^{\mathrm{a}}$ versão), extremamente necessário para a discussão, reflexão e ação em processos que movimentam a sociedade. Ao falar sobre a temática da diversidade, o professor oportuniza ao aluno o acesso ao conhecimento e reflexão acerca de temas que envolvem questões étnicas, de gênero e sexual, entre outras, promovendo debates e a desconstrução de estereótipos, criando assim diálogos com a comunidade escolar. (ESTEIO, 2017).

Essas orientações sobre as temáticas da diversidade estão em consonância com o que nos determina as Diretrizes Curriculares Nacionais (DCNs) da ERER (Parecer 03/2004), em que se estabelecem as principais ações que as instituições escolares devem seguir para implementação desta política educacional, sendo elas:

(...) a inclusão, a valorização das diferenças e o atendimento à pluralidade e à diversidade cultural resgatando e respeitando as várias manifestações de cada comunidade (BRASIL, 2004).

Além disso, a BMCC preconiza que em cada ano escolar, conforme a necessidade de cada escola, este tema poderá ser abordado desde a diversidade ligada à própria sala de aula até a diversidade que transcende os muros escolares, seguindo para a diversidade do bairro, município, estado, país e mundo. A marca da origem de cada um e do outro se tornará um fator de orgulho e de coletividade (ESTEIO, 2017). Porém, o documento cita que o tema Diversidade deverá ser trabalhado de forma mais 
significativa no currículo na Educação Infantil e no $1^{\circ}, 5^{\circ}$ e $9^{\circ}$ ano do Ensino Fundamental (ESTEIO, 2017). A questão que surge a partir disso é: tratando-se de uma temática tão urgente e necessária para entendimento da nossa sociedade, não seria coerente tratar desse assunto em todos os anos escolares do currículo?

Segundo Silva (2011, p.103) pode-se dizer que o currículo é também questão de poder, ou seja, selecionar e privilegiar determinado tipo de conhecimento é uma operação de poder. Em outras palavras, o currículo não se estabelece como um corpo neutro, inocente e desinteressado de conhecimentos. A questão da representatividade não está desvinculada da questão do poder em nossa sociedade, sendo a seleção um fator que constitui o resultado de um processo que reflete os interesses particulares das classes e grupos dominantes.

É através do currículo que educador e educando buscam possibilidades de analisar os diversos significados do cotidiano. Desta maneira, questiona-se por que não dar uma maior atenção para a temática étnico-racial em todas as suas etapas. De acordo com as Diretrizes da Lei $n^{\circ} 11.645 / 2008$, que inclui no currículo oficial da rede de ensino a obrigatoriedade da temática "História e Cultura Afro-brasileira e Indígena", o conteúdo referente ao tema deve estar presente em todo o currículo escolar, conforme o trecho:

$\S 2^{\circ}$ os conteúdos referentes à história e cultura afro-brasileira e dos povos indígenas brasileiros serão ministrados no âmbito de todo o currículo escolar, em especial nas áreas de educação artística e de literatura e história brasileiras." (BRASIL, 2008, s/p.).

Porém, dados do Centro de Estudos das Relações de Trabalho e Desigualdades (CEERT) apontam que discutir o racismo não faz parte de projetos temáticos em $24 \%$ das escolas públicas do Brasil. Os dados foram obtidos a partir do questionário do Censo Escolar de 2015, aplicado pelo Instituto Nacional de Estudos e Pesquisas Educacionais Anísio Teixeira (Inep), do qual 52 mil diretores de escolas participaram, e nos mostram que em 12 mil delas não existem projetos com a temática do racismo.

É preciso incorporar em nosso trabalho cotidiano como docente o discurso da diferença não como desvio, mas como algo que enriquece nossas práticas e as relações entre as crianças, possibilitando, desde cedo, o enfrentamento de práticas de racismo, a construção de posturas mais abertas às diferenças e, consequentemente, para a construção de uma sociedade mais plural (ABRAMOWICZ et al., 2006). Para que isto aconteça, é importante que docentes se façam presentes na elaboração de documentos 
norteadores em sala de aula e que deem maior visibilidade à temática racial, contemplando e reconhecendo os diferentes grupos sociais. Reconhecimento este que requer mudança nos discursos, raciocínios, lógicas, gestos, posturas e no modo de tratar as pessoas negras (BRASIL, 2004).

\section{CONSIDERAÇÕES FINAIS}

O racismo é uma construção histórica, social e cultural, fruto de um longo processo ideológico que foi cristalizando-se aos poucos. De acordo com o Programa Nacional de Direitos Humanos, "Racismo é uma ideologia que postula a existência de hierarquia de raça entre os grupos humanos" (BRASIL, 1998).

Ao longo da História do Brasil, as populações de origem africana sofreram com o apagamento de suas histórias e culturas, registradas e relatadas na maioria dos livros sob o viés eurocêntrico que traz uma análise superficial sobre a participação efetiva das populações de origem africana e sua trajetória histórica na construção sociocultural do país. Infelizmente, a desigualdade racial ainda persiste em nossa sociedade e, consequentemente, acaba por adentrar nos espaços escolares.

Desse modo, enquanto não colocarmos a Educação como o ponto central dessa mudança, não teremos uma sociedade socioeconomicamente mais justa. Quando o processo de ensino-aprendizagem não é permeado pelas temáticas de valorização étnico-racial, os alunos não conhecem e não compreendem a dimensão histórica da diversidade que forma a sociedade brasileira, tornando possível a reprodução do racismo e incapacitando-os de confrontá-lo. Portanto, é de suma importância a investigação dos currículos e a aplicação das devidas diretrizes e mecanismos que reeduquem as relações étnico-raciais. Relações estas que promovam e reconheçam a História e a cultura de africanos e afrodescendentes, cujas experiências e corpos foram violentamente associados como escravos, subalternos, inferiores. Conhecer e valorizar essa cultura significa identificar-se com a própria história do Brasil e com as raízes que formam o povo brasileiro.

Com a presente pesquisa, foi possível constatar que a temática não é abordada em todas as etapas do currículo do ensino básico da cidade de Esteio e há a delimitação de séries específicas para inserção do tema em sala de aula $\left(1^{\circ}, 5^{\circ}\right.$ e $9^{\circ}$ ano do Ensino 
Fundamental). Ao mencionar a preservação das diversidades, o documento atua no sentido de combater o preconceito em todas as formas, entre elas o racismo, porém ocorre ausência de orientações que viabilizem uma educação multicultural que atue no sentido de reeducar para as relações étnico-raciais. Na área de Matemática, por exemplo, não foi descrita nenhuma ação pertinente à temática. Entretanto, foram citadas neste trabalho maneiras de inserir didáticas de abordagens matemáticas utilizando exemplos advindos de outras culturas, neste caso a africana.

Portanto, pode-se verificar que a temática racial ainda não conseguiu conquistar um espaço de destaque na prática pedagógica e que existem lacunas visíveis, como pudemos analisar, na Base Municipal Comum Curricular do município de Esteio. Isso demonstra a necessidade em estarmos atentos à capacitação de nossos docentes para que estes estejam aptos a discutir o racismo com crianças e adolescentes durante todo o percurso escolar e que, principalmente, se sintam empoderados e preparados a exercer uma prática pedagógica antirracista.

Com o devido conhecimento, e como bem nos alertava Freire, "não há docência sem discência" (2003, p. 21-46), é possível criar maneiras de abordagens antirracistas em sala de aula e que provoquem a discussão sobre as questões raciais na escola, no bairro, no município, no país. O racismo não está presente apenas no espaço escolar, está vinculado em toda a sociedade e estimulando processos identitários. Ao ser possibilitado à criança reconhecer sua própria história, será possível, então, que esta venha a respeitar suas raízes culturais e que desta forma não se naturalize qualquer ambiente racista.

\section{REFERÊNCIAS}

ABRAMOWICZ, Anete et. al. Trabalhando a diferença na educação infantil. São Paulo: Moderna, 2006.

BRASIL. Ministério da Educação e Cultura. Secretaria de Educação Fundamental. Parâmetros Curriculares Nacionais. Brasília: MEC, 1998.

BRASIL. Parecer CNE/CP n. ${ }^{\circ}$ 03, de 10 de março de 2004. Diretrizes Curriculares Nacionais para a Educação das Relações Étnico-Raciais e para o Ensino de História e Cultura Afro-Brasileira e Africana. Brasília: MEC, 2004. Disponível em: http://portal.inep.gov.br/informacaodapublicacao//asset_publisher/6JYIsGMAMkW1/do cument/id/488171. Acesso em: 23 abr. 2020. 
BRASIL. Ministério da Educação / Secretaria da Educação Continuada, Alfabetização e Diversidade. Orientações e Ações para Educação das Relações Étnico-Raciais. Brasília: SECAD, 2006.

BRASIL. Lei $\mathrm{n}^{\circ} 11.645$, de 10 de março de 2008. Inclui no currículo oficial da rede de ensino a obrigatoriedade da temática "História e Cultura Afro-brasileira e Indígena”. Diário Oficial da União, Brasília, 11 de março de 2008, Seção 1, p. 1.

BRASIL. Conselho Nacional de Educação/Conselho Pleno. Parecer nº 14, 6 de junho de 2012. Estabelece Diretrizes Curriculares Nacionais para a Educação Ambiental. Diário Oficial da União, Brasília, 15 de junho de 2012, Seção 1, p. 18.

BRASIL. Ministério da Educação, Base Nacional Comum Curricular: Educação é a Base. Disponível em: http://basenacionalcomum.mec.gov.br/a-base. Acesso em: 30 jul. 2020.

BRASIL. Ministério da Educação, Comitê debate texto final da Base Comum e do ensino médio. Disponível em: http://portal.mec.gov.br/component/tags/tag/36402-basenacional-comum-curricular. Acesso em: 20 mai. 2020.

BRASIL. Ministério da Educação, Instituto Nacional de Estudos e Pesquisas Educacionais. Sinopse Estatística da Educação Básica/Censo Escolar 2014. Brasília: MEC/INEP, 2014.

CARTH, John. A Base Nacional Comum Curricular e a aplicação da política de Educação para Educação das Relações Etnico-Raciais. São Paulo, 2018.

CEERT. Centro de Estudo das Relações de Trabalho e Desigualdade. Racismo e desigualdade não são discutidos em todas as escolas. Disponível em: https://ceert.org.br/noticias/educacao/21483/racismo-e-desigualdade-nao-saodiscutidosem-todas-as-escolas. Acesso em: 14 jun. 2020.

ESTEIO. Prefeitura Municipal, Base comum curricular: uma construção reflexiva, dialógica e coletiva, Secretaria Municipal de Educação. Porto Alegre: Gênese, 2017.

FREIRE, Paulo. Pedagogia da Autonomia - saberes necessários à prática educativa. São Paulo: Paz e Terra, 2003.

GOMES, Nilma. O Movimento Negro educador: saberes construídos nas lutas por emancipação. Petrópolis, RJ: Vozes, 2017.

IBGE. Agência IBGE Notícias - PNAD Contínua 2018: educação avança no país, mas desigualdades raciais e por região persistem. Brasil, 2018. Disponível em: https://agenciadenoticias.ibge.gov.br/agenciasaladeimprensa/2013agenciadenoticias/rele ases/24857-pnad-continua-2018-educacao-avanca-no-pais-masdesigualdades-raciais-epor-regiao-persistem. Acesso em: 14 jun. 2020. 
LÜDKE, Menga; ANDRÉ, Marli. Pesquisa em educação: abordagens qualitativas. São Paulo: EPU, 1986.

MUNANGA, Kabengele. Educação e Diversidade Cultural. Caderno Penesb, n. 10, jan/jun, Rio de Janeiro, 2008/2010.

NEIRA, Marcos. Incoerências e Inconsistências da BNCC de Educação Física. In: Revista Brasileira de Ciências do Esporte, v.40 - n.3. São Paulo. 2018. Disponível em: http://rbceonline.org.br/pt/incoerenciaseinconsistenciasdabncc/articulo/S010132891830 0374/. Acesso em: 29 jul. 2020.

SILVA, Tomaz. Documentos de identidade: uma introdução às teorias do currículo. 3. ed. Belo Horizonte: Autêntica, 2011.

SILVA, Amanda. Sentimentos de pertencimento e identidade no ambiente escolar. In: Revista Brasileira De Educação Em Geografia. São Paulo. 2019. Disponível em: http://www.revistaedugeo.com.br/ojs/index.php/revistaedugeo/article/view/535. Acesso em: 16 jan. 2021.

VERRANGIA, Douglas. Conhecimentos tradicionais de matriz africana e afrobrasileira no ensino de ciências: um grande desafio. In: Revista África e Africanidades. Ano 2 - n. 8, Rio de Janeiro, 2010. Disponível em: https://www.africaeafricanidades.com.br/documentos/conhecimentos_tradicionais_matr iz_afro-brasileira_ensino_ciencias.pdf. Acesso em: 30 jul. 2020. 